\title{
Colistin Resistance $₫$ Enterobacteriaceae Isolated from Arthropods in Gifu City, Japan
}

Jusitce Opare Odoi

Gifu Daigaku

Miku Yamamoto

Gifu Daigaku

Michiyo Sugiyama

Gifu Daigaku

Tetsuo Asai ( $\boldsymbol{\nabla}$ tasai@gifu-u.ac.jp )

Gifu Daigaku https://orcid.org/0000-0002-4109-1215

Research article

Keywords: Arthropods, colistin, Enterobacteriaceae, two-component system

Posted Date: June 12th, 2020

DOI: https://doi.org/10.21203/rs.3.rs-32828/v1

License: (c) (i) This work is licensed under a Creative Commons Attribution 4.0 International License. Read Full License 


\section{Abstract \\ Background}

The emergence of antimicrobial-resistant (AMR) bacteria is an important concern for public and livestock health. Arthropods may serve as vectors that disseminate AMR bacteria across different environments. We examined the phenotype and genotype of antimicrobial resistance in Enterobacteriaceae collected from arthropods in Gifu city, Japan.

\section{Results}

A total of 186 Enterobacteriaceae from 94 arthropods were obtained and tested for antimicrobial susceptibility. All isolates were susceptible to the antimicrobial agents tested, except for colistin (39 isolates) and kanamycin (one isolate). The aph(3')-la gene and amino acid substitutions in the twocomponent system were responsible for the kanamycin and colistin resistance, respectively.

\section{Conclusion}

Overall Enterobacteriaceae isolated from the arthropods were susceptible to most of the antimicrobial agents. However, a high prevalence of colistin resistance was observed in the isolates from the arthropods. We suspect that this was a result of the production of antimicrobial peptides by the arthropods rather than selective pressure or exposure to colistin in the environment. Thus, arthropods maybe a potential reservoir of colistin resistant bacteria. These findings could be beneficial to public and livestock health management.

\section{Background}

The wide occurrence of antimicrobial-resistant (AMR) bacteria in various fields such as medicine, veterinary, and agriculture is of great concern and necessitates investigation into emerging AMR bacteria in various environments. Arthropods are a group of ubiquitous creatures including Hexapoda (insects in a broad sense), Crustacea such as pill bugs, Chelicerata such as spiders and Myriapoda such as centipedes that interact extensively with their environment [1]. They generally harbor complex microbial communities, and both gram-negative (Enterobacter spp., Klebsiella spp.) and grampositive bacteria (Enterococcus spp., Staphylococcus spp.) resistant to antimicrobial agents have been isolated from them [2].

Colistin (CST) is used as a last resort for the treatment of multi-drug-resistant gram-negative bacteria. The initial mode of action for CST is to attach to a negatively charged component of the lipopolysaccharides (LPS) found in gram-negative bacteria cell membranes. It competitively displaces divalent cations $\left(\mathrm{Ca}^{2+}\right.$ and $\left.\mathrm{Mg}^{2+}\right)$ from the phosphate groups of membrane lipids, resulting in the disruption of the outer cell membrane that leads to a leakage of intracellular contents and bacterial cell death [3]. Gram-negative bacteria use different strategies, including genetic mutations in the PhoPQ/PmrAB two-component system and acquisition of the plasmidic mobile colistin resistant gene $(\mathrm{mcr})$, to achieve modification of the LPS [4]. The mutations in the PhoPQ/PmrAB two-component system result in the reduction of the binding affinity of CST through the addition of either phosphoethanolamine or 4-amino-4-deoxy-L-arbinose to the lipid A moiety of the LPS which increases the net positive charge, whereas the $m c r$ can only lead to addition of phosphoethanolamine to the LPS resulting in an increase in net positive charge but this can confer high CST resistance [5].

Arthropods produce antimicrobial peptides to perform various functions including prevention of bacterial infections and mediating symbiotic relationships between the host and beneficial bacteria [6]. It could therefore be expected that the symbiotic bacteria of arthropods have developed resistance to antimicrobial peptides. Antimicrobial peptides exhibit a similar mode of action to CST against gram-negative bacteria as described above. The difference is that antimicrobial peptides can also translocate into the cytoplasm and interrupt essential intracellular processes resulting in bacteria death [7].

Arthropods may serve as vectors that disseminate AMR bacteria across different environments. For example, houseflies have been associated with the maintenance and dissemination of cephalosporin and colistin resistant Enterobacteriaceae [8]. In another study, multi-drug-resistant bacterial species were isolated from cockroaches [9]. Enterobacteriaceae are prevalent in the intestinal tract of humans and animals [10]. Members of this family have been opportunistically implicated in blood-stream, intra-abdominal, skin, soft-tissue, and urinary tract infections [11]. We examined the phenotype and genotype of antimicrobial resistance in Enterobacteriaceae from arthropods in order to better understand the emergence of AMR bacteria in the environment.

\section{Materials And Methods}

A total of 94 arthropods comprising Hexapoda $(n=49)$, Myriapoda $(n=32)$, Chelicerata $(n=10)$, and Crustacea $(n=3)$ were collected at Gifu university and Mount Kinka in Gifu city, Japan between 2016 and 2018 (Table 1). Flying and walking arthropods were caught using net traps and forceps, respectively, then euthanized using carbon dioxide in separate bags [12] and were returned to the laboratory for bacterial isolation from the arthropods' whole body. Bacterial isolation was performed using deoxycholate hydrogen sulfide lactose agar medium and incubated at $37{ }^{\circ} \mathrm{C}$ overnight. API20E (BioMerieux Tokyo, Japan) was used for bacterial identification. The minimum inhibitory concentration was determined using frozen plates (Eiken Chemical Co., Ltd., Tokyo, Japan) according to the manufacturer's instructions. The following 10 antimicrobial agents were tested: cefotaxime (CTX, 
0.5-64 $\mu \mathrm{g} / \mathrm{mL})$, meropenem (MEM, 0.25-32 $\mu \mathrm{g} / \mathrm{mL})$, gentamicin (GEN, 0.5-64 $\mu \mathrm{g} / \mathrm{mL})$, kanamycin (KAN, 1-128 $\mu \mathrm{g} / \mathrm{mL})$, tetracycline (TET, 0.5-

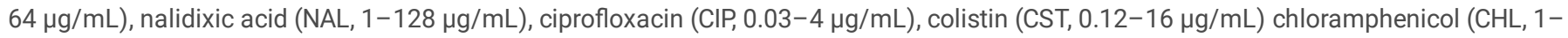
$128 \mu \mathrm{g} / \mathrm{mL}$ ), and sulfamethoxazole-trimethoprim (SXT, 2.38/0.12-152/8 $\mu \mathrm{g} / \mathrm{mL}$ ). Clinical and Laboratory Standards Institute guideline breakpoints [13] were used for all antimicrobials except for CST. The European Committee on Antimicrobial Susceptibility Testing (EUCAST) resistance breakpoints [14] were used for CST.

Table 1

Classification and number of arthropods used in the study

\begin{tabular}{|c|c|c|c|c|c|}
\hline Subphylum & Order & Family & English names & Scientific name & \\
\hline & & & & & Total sample \\
\hline \multirow[t]{15}{*}{ Hexapoda } & \multirow[t]{2}{*}{ Orthoptera } & Acrididae & Grasshopper & Hieroglyphus daganensis & $9 / 9(100)$ \\
\hline & & Gryllidae & Cricket & Meloimorpha japonica & $2 / 2(100)$ \\
\hline & \multirow[t]{5}{*}{ Coleoptera } & Lucanidae & Stag beetle & Lucanus maculifemeratus & $4 / 5(80)$ \\
\hline & & Tenebrionidae & Mealworm & Tenebrio molitor & $5 / 7(71.4)$ \\
\hline & & Tenebrionidae & Darkling beetle & Allecula melanaria & $0 / 1(0)$ \\
\hline & & Scarabaeidae & Dung beetle & Popillia japonica & $2 / 2(100)$ \\
\hline & & Subtotal & & & 14/18(78) \\
\hline & \multirow[t]{4}{*}{ Hemiptera } & Reduviidae & Assassin bug & Agriosphodrus dohrni & $2 / 5(40)$ \\
\hline & & Pentatomidae & Stink bug & Halyomorpha halys & $0 / 1(0)$ \\
\hline & & Cicadellidae & Leafhopper & Orientus ishidae & $0 / 1(0)$ \\
\hline & & Subtotal & & & 2/7(29) \\
\hline & \multirow[t]{2}{*}{ Lepidoptera } & Papilionidae & Butterfly & Luehdorfia japonica & $1 / 1(100)$ \\
\hline & & Pieridae & White butterfly & Peris rapae & $0 / 2(0)$ \\
\hline & Mantodea & Mantidae & Praying mantis & Tendora sinensis & $1 / 1(100)$ \\
\hline & Subtotal & & & & $34 / 49(69.4)$ \\
\hline \multirow[t]{3}{*}{ Myriapoda } & Polydesmida & Eurymerodesmidae & Millipede & Eurymerodesmus spp. & 11/11(100) \\
\hline & Scutigeromorpha & Scutigeridae & Centipede & Thereuonema tuberculata & $13 / 21(62)$ \\
\hline & Subtotal & & & & $24 / 32(75)$ \\
\hline Chelicerata & Araneae & Liphistiidae & Spider & Heptathela kimurai & $0 / 10(0)$ \\
\hline Crustacea & Isopod & Armadillidiidae & Pill bugs & Armadillidium vulgare & $3 / 3(100)$ \\
\hline Total & & & & & 61/94(64.9) \\
\hline
\end{tabular}

Whole genome sequencing (WGS) was conducted on one CST-resistant Enterobacter spp. and one KAN-resistant Klebsiella spp. by Illumina Miseq sequencer (Illumina, California, USA) according to the manufacturer's instructions. Resistance genes and plasmids were investigated using ResFinder [15] and PlasmidFinder [16]. The $m c r-1, m c r-2, m c r-3, m c r-4$, and $m c r-5$ genes were investigated in all CST-resistant isolates using primers described elsewhere [17-19]. In addition, amino acid substitution in the two-component system genes (phoP, phoQ, pmrA, and pmrB) associated with CST resistance in Enterobacter spp. were investigated using primers (Table 2) based on a sequence of CST-resistant Enterobacter spp. using eurofins 
genome primer design tool [20]. A comparison of the sequences of the genes; phoP, phoQ, pmrA, and pmrB, in our CST resistant isolates, CST susceptible isolates, and those of CST susceptible reference sequence Enterobacter cloacae ATCC 13047(CP001918) was performed using T-coffee software [21] to identify amino acid substitution.

\section{Statistical analysis}

Chi squared $(\chi 2)$ tests were performed to determine difference in CST resistance among the group of arthropods. A p-value of $<0.05$ was determined to be significant.

Table 2

Primers used to amplify two-component system genes

\begin{tabular}{|cll|}
\hline Gene & Primer name & Sequence $\left(\mathbf{5}^{\prime}\right.$-3') \\
\hline phoP & phoPfoward & CGTACTGGTTGTTGAGGATAACGC \\
\cline { 2 - 3 } & phoPreverse & TTAGCGTAATTCGAACAGGTAGCC \\
\hline phoQ & phoQforward & GGGTTCGTTTCTTACTGGCAAC \\
& phoQreverse & TTAACTATCGTTCAATGTGGGCTG \\
pmrA & pmrAforward & GTTGAAGACGATCTGTTATTGC \\
& $\begin{array}{lll}\text { pmrAreverse } \\
\text { pmrB }\end{array}$ & TTTCTGGCTCTCCAGACGGTAG \\
pmrB & pmrBreverse & AGCTGGCGATCAAACCACCTTC \\
\hline
\end{tabular}

\section{Results And Discussion}

Enterobacteriaceae were isolated from 61 of the 94 arthropods: 3 of 3 Crustacea samples, 24 of 32 Myriapoda samples and 34 of 49 Hexapoda samples (Table 1). In total, 186 isolates were obtained: 114 from Hexapoda, 64 from Myriapoda, and 8 from Crustacea (Table 3 ). The most frequent bacterial species was Enterobacter spp. $(n=61)$, followed by Pantoea spp. $(n=26)$, Cedecea spp. $(n=18)$, Serratia spp. $(n=18)$, Hafnia spp. $(n=16)$, and Klebsiella spp. $(n=13)$. In this study, diverse Enterobacteriaceae were isolated from the arthropods. Enterobacter spp., the predominant bacteria isolated, have been responsible for intraperitoneal infection in humans [10]. The next most frequently isolated Enterobacteriaceae - Pantoea spp., Hafnia spp., Serratia spp., Cedecea spp., and Klebsiella spp. have been associated with opportunistic infections in humans. K. pneumoniae and K. oxytoca are known to cause urinary tract infections, pneumonia, and sepsis in patients with compromised immunity [11]. In contrast, some arthropods are known to form symbiotic relationship with these Enterobacteriaceae species to enable the breakdown of ingested food such as cellulose for easy digestion and nutrient assimilation [22]. 
Table 3

Bacterial species isolated from arthropods

\begin{tabular}{|c|c|c|c|c|c|}
\hline \multicolumn{2}{|l|}{ Bacteria } & \multicolumn{4}{|c|}{ Subphylum: Sample No. (Isolate No.) } \\
\hline Genus & Species & Hexapoda & Myriapoda & Crustacea & Total \\
\hline \multirow[t]{5}{*}{ Enterobacter } & cloacae & $13(24)$ & $2(4)$ & $1(1)$ & $15(29)$ \\
\hline & amnigenus & $4(6)$ & $12(20)$ & 0 & $16(26)$ \\
\hline & aerogenes & $1(1)$ & $2(2)$ & 0 & $3(3)$ \\
\hline & asburiae & $2(3)$ & 0 & 0 & $2(3)$ \\
\hline & Subtotal & 19(34) & $16(26)$ & $1(1)$ & $36(61)$ \\
\hline Pantoea & Pantoea spp. & 11(17) & $4(5)$ & $2(4)$ & $17(26)$ \\
\hline \multirow[t]{3}{*}{ Cedecea } & lapagei & $5(9)$ & $1(2)$ & $1(1)$ & $7(12)$ \\
\hline & davisae & $3(6)$ & 0 & 0 & $3(6)$ \\
\hline & Subtotal & $8(15)$ & $1(2)$ & $1(1)$ & $10(18)$ \\
\hline \multirow[t]{4}{*}{ Serratia } & marcescens & $6(10)$ & $1(2)$ & 0 & $7(12)$ \\
\hline & liquefaciens & 0 & $3(5)$ & 0 & $3(5)$ \\
\hline & fonticola & 0 & $1(1)$ & 0 & $1(1)$ \\
\hline & Subtotal & $6(10)$ & $4(8)$ & 0 & 11(18) \\
\hline Hafnia & Alvei & $6(13)$ & $2(3)$ & 0 & $8(16)$ \\
\hline \multirow[t]{3}{*}{ Klebsiella } & pneumoniae & $3(3)$ & $4(5)$ & 0 & $7(8)$ \\
\hline & oxytoca & $5(5)$ & 0 & 0 & $5(5)$ \\
\hline & Subtotal & $8(8)$ & $4(5)$ & 0 & 12(13) \\
\hline \multirow[t]{4}{*}{ Escherichia } & vulneris & $2(2)$ & $3(3)$ & 0 & $5(5)$ \\
\hline & Coli & 0 & $1(2)$ & 0 & $1(2)$ \\
\hline & hermannii & 0 & $1(1)$ & 0 & $1(1)$ \\
\hline & Subtotal & $2(2)$ & $5(6)$ & 0 & $7(8)$ \\
\hline Rahnella & aquatilis & $3(5)$ & $1(1)$ & 0 & $4(6)$ \\
\hline \multirow[t]{3}{*}{ Citrobacter } & freundii & $2(3)$ & 0 & 0 & $2(3)$ \\
\hline & youngae & $1(1)$ & $2(2)$ & 0 & $3(3)$ \\
\hline & Subtotal & $3(4)$ & $2(2)$ & 0 & $5(6)$ \\
\hline Cronobacter & Cronobacterspp. & $2(5)$ & 0 & 0 & $2(5)$ \\
\hline \multirow[t]{3}{*}{ Raoutella } & ornitholytica & 0 & $1(1)$ & $1(1)$ & $2(2)$ \\
\hline & planticola & 0 & $1(1)$ & 0 & $1(1)$ \\
\hline & Subtotal & 0 & $2(2)$ & $1(1)$ & $3(3)$ \\
\hline Kluyvera & intermedia & $1(1)$ & $2(2)$ & 0 & $3(3)$ \\
\hline Leclercia & adecaboxylata & 0 & $1(1)$ & $1(1)$ & $2(2)$ \\
\hline Buttiauxella & agrestis & 0 & $1(1)$ & 0 & $1(1)$ \\
\hline Total & & $34(114)$ & $24(64)$ & $3(8)$ & 61(186) \\
\hline
\end{tabular}

Arthropod-derived Enterobacteriaceae isolated in this study were susceptible to all antimicrobial agents tested except CST and KAN. CST resistance was observed in 39 (29\%) of the 134 isolates, excluding Cedecea spp., Hafnia spp. and Serratia spp. which have intrinsic resistance. The 39 isolates resistant to CST were found in Enterobacter spp. (25/61, 41.0\%), Pantoea spp. (6/26, 23.1\%), Klebsiella spp. (7/13, 53.8\%) and Escherichia spp. (1/8, 12.5\%). In Enterobacter spp., CST resistance was found in Hexapoda- grasshopper (7), cricket (2), mealworm (1), dung beetle (1), butterfly (1) and Myriapoda- millipede (1), centipede (1). In Pantoea spp., CST resistance was found in Hexapoda- grasshopper (2), earwig (2). In Klebsiella spp., CST resistance was found in Hexapoda- cricket (1), mealworm (1), assassin bug (1), earwig (1) and Myriapoda- millipede (2), centipede (1). In Escherichia 
spp., CST resistance was only found in Hexapoda- earwig (1), but no CST resistance in Crustacea (Table 4). The percentage of CST resistance was significantly high in Enterobacter isolates from Hexapoda $(19 / 34,55.9 \%)$ than Myriapoda $(6 / 26,23.1 \%$ : P $<0.05)$. Hexapods are obligate hosts of bacterial species, more so than any other group of arthropods [23], and as such, these bacterial species have developed resistance to survive the defense mechanism produced by the host [24].

Table 4

Colistin resistance observed in Enterobacteriaceae isolated from arthropods

\begin{tabular}{|c|c|c|c|c|c|c|c|c|c|c|c|c|c|}
\hline \multirow[t]{3}{*}{ Subphylum } & \multirow{3}{*}{$\begin{array}{l}\text { English } \\
\text { name }\end{array}$} & \multicolumn{12}{|c|}{ Enterobacteriaceae species: No. of Positive Samples (Isolate No.) } \\
\hline & & \multicolumn{3}{|c|}{ Enterobacterspp. } & \multicolumn{3}{|c|}{ Pantoea spp. } & \multicolumn{3}{|c|}{ Klebsiella spp. } & \multicolumn{3}{|c|}{ Escherichia spp. } \\
\hline & & $\begin{array}{l}\text { No. } \\
\text { tested }\end{array}$ & $\begin{array}{l}\text { CST } \\
\text { resistant }\end{array}$ & $\%$ & $\begin{array}{l}\text { No. } \\
\text { tested }\end{array}$ & $\begin{array}{l}\text { CST } \\
\text { resistant }\end{array}$ & $\%$ & $\begin{array}{l}\text { No. } \\
\text { tested }\end{array}$ & $\begin{array}{l}\text { CST } \\
\text { resistant }\end{array}$ & $\%$ & $\begin{array}{l}\text { No. } \\
\text { tested }\end{array}$ & $\begin{array}{l}\text { CST } \\
\text { resistant }\end{array}$ & $\%$ \\
\hline \multirow[t]{11}{*}{ Hexapoda } & Grasshopper & $9(19)$ & $7(11)$ & 57.9 & $5(9)$ & $2(3)$ & 33.3 & 0 & 0 & 0 & $1(1)$ & 0 & 0 \\
\hline & Cricket & $2(3)$ & $2(2)$ & 66.7 & $1(1)$ & 0 & 0 & $1(1)$ & $1(1)$ & 100 & 0 & 0 & 0 \\
\hline & Mealworm & $1(1)$ & $1(1)$ & 100 & 0 & 0 & 0 & $1(1)$ & $1(1)$ & 100 & 0 & 0 & 0 \\
\hline & Dung beetle & $2(2)$ & $1(1)$ & 50 & 0 & 0 & 0 & 0 & 0 & 0 & 0 & 0 & 0 \\
\hline & Click beetle & $1(2)$ & $1(1)$ & 50 & 0 & 0 & 0 & $1(1)$ & 0 & 0 & 0 & 0 & 0 \\
\hline & Stag beetle & $2(2)$ & 0 & 0 & 0 & 0 & 0 & 0 & 0 & 0 & 0 & 0 & 0 \\
\hline & Lady beetle & 0 & 0 & 0 & $1(1)$ & 0 & 0 & 0 & 0 & 0 & 0 & 0 & 0 \\
\hline & Butterfly & $1(4)$ & $1(3)$ & 75 & $1(1)$ & 0 & 0 & 0 & 0 & 0 & 0 & 0 & 0 \\
\hline & $\begin{array}{l}\text { Assassin } \\
\text { bug }\end{array}$ & $1(1)$ & 0 & 0 & 0 & 0 & 0 & $3(3)$ & $1(1)$ & 33.3 & 0 & 0 & 0 \\
\hline & Earwig & 0 & 0 & 0 & $3(5)$ & $2(3)$ & 60 & $2(2)$ & $1(1)$ & 50 & $1(1)$ & $1(1)$ & 100 \\
\hline & Subtotal & 19(34) & 13(19) & 55.9 & 11(17) & $4(6)$ & 35.3 & $8(8)$ & $4(4)$ & 50 & $2(2)$ & $1(1)$ & 50 \\
\hline \multirow[t]{3}{*}{ Myriapoda } & Millipede & $12(18)$ & $1(3)$ & 16.7 & $2(3)$ & 0 & 0 & $3(4)$ & 2(2) & 50 & $1(2)$ & 0 & 0 \\
\hline & Centipede & $4(8)$ & $1(3)$ & 37.5 & $2(2)$ & 0 & 0 & $1(1)$ & $1(1)$ & 100 & $4(4)$ & 0 & 0 \\
\hline & Subtotal & $16(26)$ & $2(6)$ & 23.1 & $4(5)$ & 0 & 0 & $4(5)$ & $3(3)$ & 60 & $5(6)$ & 0 & 0 \\
\hline Crustacea & Pill bugs & $1(1)$ & 0 & 0 & $2(4)$ & 0 & 0 & 0 & 0 & 0 & 0 & 0 & 0 \\
\hline Total & & $36(61)$ & $15(25)$ & 41 & $17(26)$ & $4(6)$ & 23.1 & $12(13)$ & $7(7)$ & 53.8 & $7(8)$ & $1(1)$ & 12.5 \\
\hline CST- colistin & & & & & & & & & & & & & \\
\hline
\end{tabular}

The $m c r-1-5$ genes were not detected in any of the CST-resistant isolates. The absence of $m c r-1-5$ gene in the CST-resistant isolates observed in this study prompted us to investigate the PhoPQ/PmrAB two-component system. We examined amino acid substitution in the PhoPQ/PmrAB twocomponent system in CST-resistant Enterobacter isolates and compared them to those of CST-susceptible Enterobacter strains. Our investigation showed various amino acid substitutions: three amino acid substitution in phoP (L129I, F141L, H207Q), five in phoQ (V102I, L133I, M298L, S448A, G464S), four in pmrA (A19G, S21A, N89T, L146Q) and four in pmrB (H132S, A172T, Q271V, R276Q). The amino acid substitutions observed in phoP, phoQ, and pmrA in this study corresponded with those reported by Uechi et al. [25]. On the other hand, the amino acid substitutions observed in this study were different from those reported in another study by Nawfal Dagher et al. [26]. We could not clarify the specific amino acid substitution responsible for the CST resistance observed. Arthropods rarely have direct contact with CST because of restrictions on CST usage for humans and pigs in Japan. Hence, the observed CST resistance was unexpected and as such it is not plausible to attribute this CST resistance to selective pressure or exposure to CST in the environment. Most arthropods have antimicrobial peptides in their hemolymph that serve as a defense mechanism and plays an important role in fostering symbiotic relationships with beneficial bacteria [6]. It therefore stands to reason that symbiotic bacteria may have developed resistance to antimicrobial peptides. The initial mode of action of antimicrobial peptides and CST against gram-negative bacteria involves binding to the LPS [6], this may have led to the development of cross-resistance to CST [27].

One isolate of $K$. oxytoca from a butterfly in this study showed resistance to KAN. WGS analysis revealed that the resistance gene aph(3')-la was located on the chromosome of K. oxytoca. The aph(3') -la gene was first discovered on transposon Tn903 in Escherichia coli [28] and has subsequently been found on plasmids and chromosomes of clinical and veterinary Enterobacteriaceae isolates [29-30]. The presence of aph(3')-la in arthropods may suggest the possibility that arthropods received this bacterium from human and/or domestic animals or vice versa.

In previous studies, Enterobacteriaceae isolated from cockroaches showed resistance to more than two antimicrobial agents [9, 31]. In Japan, Enterobacter spp. isolated from companion animals showed resistance to CTX (33.3\%), GM (23.3\%), TC (40\%), CPFX (43.3\%), and CP (46.7\%) and were 
reported to be extended spectrum beta-lactamase (ESBL) producers [32]. In addition, Klebsiella spp. isolated from companion animals were resistant to aminoglycosides and quinolones and were reported to be extended beta-lactamase producers [33]. However, susceptibility to antimicrobial agents were high, as expected in this study. The high susceptibility observed indicate an absence or low prevalence of AMR bacteria and minimal antimicrobial agents' pollution in the immediate environment of the arthropods investigated.

The present study did not compare the isolation rate of bacteria on the external surface and alimentary tract of the arthropods. However, there was no significant difference between the isolation rate of bacteria on the external surface and the alimentary tract of cockroaches in a previous report [9].

\section{Conclusion}

In conclusion, the Enterobacteriaceae isolated from the arthropods were susceptible to most of the antimicrobial agents. However, high prevalence of CST resistance was observed in the isolates from the arthropods. We suspect that this was a result of the production of antimicrobial peptides by the arthropods rather than selective pressure or exposure to CST in the environment. These findings could be beneficial to public and livestock health management as well as present novel approaches to exploring bacterial adaptations to its environment and the impact this has on the larger ecosystem.

\section{Abbreviations}

AMR- Antimicrobial-resistant

CHL- Chloramphenicol

CIP- Ciprofloxacin

CST- Colistin

CTX-Cefotaxime

EUCAST- The European Committee on Antimicrobial Susceptibility Testing

GEN- Gentamicin

KAN- Kanamycin

LPS- Lipopolysaccharides

MEM- Meropenem

NAL- Nalidixic acid

SXT- Sulfamethoxazole-trimethoprim

TET- Tetracycline

WGS- Whole genome sequencing

\section{Declarations}

\section{Ethics approval and consent to participate}

Not applicable

\section{Consent for publication}

Not applicable

\section{Availability of data}

The sequence datasets generated and analyzed during the current study have been deposited into DDBJ/EMBL/GenBank databases (https://www.ncbi.nlm.nih.gov/nuccore/)under the accession number: MN944620 to MN944643 and MN944719 (pmrB gene), MN944644 to MN944668 (pmrA gene), MN944669 to MN944693 (phoP gene), and MN944694 to MN944718 (phoQ gene).

\section{Competing interests}

The authors declare that they have no competing interests. 


\section{Funding}

This study was supported by JSPS KAKENHI (grant number 18H04073) and JOO is a beneficiary of a Japanese government (MEXT) scholarship.

\section{Authors' contribution}

MY and MS performed sample collection and laboratory work. JOO processed and analyzed sequence data. JOO and TA wrote the manuscript. All authors read and approved the manuscript.

\section{Acknowledgement}

We would like to thank Editage (www.editage.com) for English language editing.

\section{References}

1. Gonçalves MF, Pereira JA. Abundance and diversity of soil arthropods in the olive grove ecosystem. J Insect Sci. 2012;12:20.

2. Šrámová $H$, Daniel $M$, Absolonová V, Dědičová $D$, Jedličková Z, Lhotová $H$, et al. Epidemiological role of arthropods detectable in health facilities. J Hosp Infect. 1992;20:281-92.

3. Poirel L, Jayol A, Nordmann P. Polymyxins: antibacterial activity, susceptibility testing, and resistance mechanisms encoded by plasmids or chromosomes. Clin Microbiol Rev. 2017;30:557-96.

4. Olaitan AO, Morand S, Rolain JM. Mechanisms of polymyxin resistance: acquired and intrinsic resistance in bacteria. Front Microbiol. $2014 ; 5: 643$.

5. Aghapour Z, Gholizadeh P, Ganbarov K, Bialvaei AZ, Mahmood SS, Tanomand A, et al. Molecular mechanisms related to colistin resistance in Enterobacteriaceae. Infect Drug Resist. 2019;12:965-75.

6. Rolff J, Schmid-Hempel P. Perspectives on the evolutionary ecology of arthropod antimicrobial peptides. Philos Trans R Soc Lond B Biol Sci. 2016;371:20150297.

7. Jenssen H, Hamill P, Hancock REW. Peptide antimicrobial agents. Clin Microbiol Rev. 2006;19:491-511.

8. Fukuda A, Usui M, Okubo T, Tagaki C, Sukpanyatham N, Tamura Y. Co-harboring of cephalosporin (bla)/colistin (mcr) resistance genes among Enterobacteriaceae from flies in Thailand. FEMS Microbiol Lett. 2018;365:fny178.

9. Wannigama DL, Dwivedi R, Zahraei-Ramazani A. Prevalence and antibiotic resistance of gram-negative pathogenic bacteria species isolated from Periplaneta americana and Blattella germanica in Varanasi, India. J Arthropod-Borne Dis. 2013;8:10-20.

10. Davin-Regli A, Jean-Marie P. Enterobacter aerogenes and Enterobacter cloacae, versatile bacterial pathogens confronting antibiotic treatment. Front Microbiol. 2015;6:392.

11. Paterson DL. Resistance in gram-negative bacteria: Enterobacteriaceae. Am J Med. 2006;34:20-8.

12. Bennie NA, Loaring CD, Bennie MMG, Trim SA. An effective method for terrestrial arthropod euthanasia. J Exp Biol. 2012;215:4237-41.

13. Clinical and Laboratory Standards. Institute (CLSI) performance standards for antimicrobial susceptibility testing. 26th Ed. CLSI supplement M100S. Wayne: Clinical and Laboratory Standards Institute;2016.

14. The European Committee on Antimicrobial Susceptibility Testing (EUCAST). Routine and extended internal quality control for MIC determination and disk diffusion as recommended by EUCAST. Version 7.0. 2017.http://www.eucast.org. Accessed 22 Jan 2018.

15. Zankari E, Hasman H, Cosentino S, Vestergaard M, Rasmussen S, Lund O, et al. Identification of acquired antimicrobial resistance genes. J Antimicrob Chemother. 2012;67:2640-4.

16. Carattoli A, Zankari E, García-Fernández A, Larsen MV, Lund O, Villa L, et al. In silico detection and typing of plasmids using PlasmidFinder and plasmid multilocus sequence typing. Antimicrob Agents Chemother. 2014;58:3895-903.

17. Borowiak M, Fischer J, Hammerl JA, Hendriksen RS, Szabo I, Malorny B. Identification of a novel transposon-associated phosphoethanolamine transferase gene, mcr-5, conferring colistin resistance in d-tartrate fermenting Salmonella enterica subsp. enterica serovar Paratyphi B. J Antimicrob Chemother. 2017;72:3317-24.

18. Carattoli A, Villa L, Feudi C, Curcio L, Orsini S, Luppi A, et al. Novel plasmid-mediated colistin resistance mcr-4 gene in Salmonella and Escherichia coli, Italy 2013, Spain and Belgium, 2015 to 2016. Euro Surveill. 2017;22:31.

19. Zhang J, Chen L, Wang J, Yassin AK, Butaye P, Kelly P, et al. Molecular detection of colistin resistance genes (mcr-1, mcr-2 and mcr-3) in nasal/oropharyngeal and anal/cloacal swabs from pigs and poultry. Sci Rep. 2018;8:370.

20. Eurofins genomics. https://www.eurofinsgenomics.eu/en/ecom/tools/pcr-primer-design. Accessed 28 Oct 2019.

21. Notredame C, Higgins DG, Heringa J. T-Coffee: A novel method for fast and accurate multiple sequence alignment. J Mol Biol. 2000;302:205-17.

22. Paniagua Voirol LR, Frago E, Kaltenpoth M, Hilker M, Fatouros NE. Bacterial symbionts in Lepidoptera: Their diversity, transmission, and impact on the host. Front Microbiol. 2018;9:556-6.

23. Horváthová T, Kozłowski J, Bauchinger U. Growth rate and survival of terrestrial isopods is related to possibility to acquire symbionts. Eur J Soil Biol. 2015;69:52-6. 
24. Cole JN, Nizet V. Bacterial evasion of host antimicrobial peptide defenses. Microbiol Spectr. 2016;4:10.1128.

25. Uechi K, Tada T, Shimada K, Nakasone I, Kirikae T, Fujita J. Emergence of a carbapenem-resistant and colistin-heteroresistant Enterobacter cloacae clinical isolate in Japan. $J$ Infect Chemother. 2019;25:285-8.

26. Nawfal Dagher T, Al-Bayssari C, Chabou S, Baron S, Hadjadj L, Diene SM, et al. Intestinal Carriage of Colistin Resistant Enterobacteriaceae at Saint Georges Hospital in Lebanon. J Glob Antimicrob Resist. 2019;7165:30315-7.

27. Hashemi MM, Holden BS, Coburn J, Taylor MF, Weber S, Hilton B, et al. Proteomic analysis of resistance of gram-negative bacteria to chlorhexidine and impacts on susceptibility to colistin, antimicrobial peptides, and ceragenins. Front Microbiol. 2019;10:210.

28. Oka A, Sugisaki H, Takanami M. Nucleotide sequence of the kanamycin resistance transposon Tn903. J Mol Biol. 1981;147:217-26.

29. Miró E, Grünbaum F, Gómez L, Rivera A, Mirelis B, Coll P, Navarro F. Characterization of aminoglycoside-modifying enzymes in Enterobacteriaceae clinical strains and characterization of the plasmids implicated in their diffusion. Microbial Drug Resist. 2013;19:94-9.

30. Belaynehe KM, Shin SW, Hong-Tae P, Yoo HS. Occurrence of aminoglycoside-modifying enzymes among isolates of Escherichia coli exhibiting high levels of aminoglycoside resistance isolated from Korean cattle farms. FEMS Microbiol Lett. 2017;364:fnx129.

31. Pai HH, Chen WC, Peng CF. Isolation of bacteria with antibiotic resistance from household cockroaches (Periplaneta americana and Blattella germanica). Acta Trop. 2005;3:259-65.

32. Harada K, Shimizu T, Mukai Y, Kuwajima K, Sato T, Kajino A, et al. Phenotypic and molecular characterization of antimicrobial resistance in Enterobacter spp. isolates from companion animals in Japan. PLOS ONE. 2017;12:e0174178.

33. Harada K, Shimizu T, Mukai Y. Kuwajima K, Sato T, Usui M, et al. Phenotypic and molecular characterization of antimicrobial resistance in Klebsiella spp. isolates from companion animals in Japan: Clonal dissemination of multidrug-resistant extended spectrum beta-lactamase producing Klebsiella pneumoniae. Front Microbiol. 2016;7:1021. 